\title{
Incidence of Shivering after Cesarean Section under Spinal Anesthesia with or without Intrathecal Sufentanil: A Randomized Study
}

\author{
Giovani de Figueiredo Locks ${ }^{1}$
}

Summary: Giovani de Figueiredo Locks - Incidence of Shivering after Cesarean Section under Spinal Anesthesia with or without Intrathecal Sufentanil: A Randomized Study.

Background and objectives: Shivering is a cause of discomfort and dissatisfaction in patients undergoing cesarean section. The objective of this study paper was to assess the impact of intrathecal administration of sufentanil on the incidence of shivering after cesarean section.

Method: In a prospective blinded, randomized clinical trial, pregnant women undergoing cesarean section under spinal anesthesia were enrolled. Pregnant women in labor, febrile, obese, with pregnancy-induced hypertension, anesthetic block failure or surgical complications were excluded. Patients were randomly assigned to two groups. In Group I, $10 \mathrm{mg}$ of $0.5 \%$ hyperbaric bupivacaine combined with $80 \mathrm{mcg}$ of morphine and $2.5 \mathrm{mcg}$ of sufentanil were administered. In Group II, $10 \mathrm{mg}$ of $0.5 \%$ hyperbaric bupivacaine combined with 80 mcg of morphine were administered. In the post-anesthesia care unit, patients were evaluated for signs of shivering by an investigator blinded to the patient's group allocation.

Results: The sample consisted of 80 patients. In both groups there was a decrease in axillary temperature of patients after cesarean section ( $p<$ 0.001). This decrease was not different between groups ( $<0.21)$. In Group I, the incidence of tremor was $32.5 \%(13 / 40)$ and in Group II it was $62.5 \%(25 / 40)(p<0.007)$; RR 0.53 (Cl 95\% 0.32-0.87).

Conclusions: It has been suggested that the addition of sufentanil to hyperbaric bupivacaine and morphine during spinal anesthesia for cesarean section provides a decrease in the incidence of shivering in the immediate postoperative period.

Keywords: Cesarean Section; Anesthesia, Spinal; Shivering; Sufentanil.

(02012 Elsevier Editora Ltda. All rights reserved.

\section{INTRODUCTION}

Unintentional hypothermia, defined as central blood temperature below $36^{\circ} \mathrm{C}$, often occurs during anesthesia and surgery due to various factors. The main ones are the direct inhibition of thermoregulation by anesthetic, decreased metabolism, patient exposure to cold environment of operating rooms, and body cavity exposure ${ }^{1}$. There is evidence that perioperative hypothermia is associated with severe outcomes. Increased incidence of wound infection, greater intraoperative blood loss, need for blood transfusion, increased incidence of cardiac events, long acting drugs, postoperative shivering, increase in post-anesthetic recovery, greater adrenergic activation, and increased incidence of thermal discomfort are associated with hypothermia ${ }^{2}$.

Received from Maternidade Carmela Dutra, Universidade Federal de Santa Catarina, Florianópolis, SC, Brazil.

1. Anesthesiologist; Maternidade Carmela Dutra, Universidade Federal de Santa Catarina, Florianópolis, SC, Brazil

Submitted on February 23, 2012

Approved on June 4, 2012.

Correspondence to:

Giovani de Figueiredo Locks, MD

Maternidade Carmela Dutra

Serviço de Anestesiologia

Rua Irmã Benwarda s/n

Centro

88000000 - Florianópolis, SC Brazil.

E-mail: giovanilocks@gmail.com
Shivering is a protective reflex that increases the production of body heat through muscle contraction. Its side effects are increased oxygen consumption as well as levels of pain and interference with monitoring ${ }^{3}$. Shivering, along with pain, nausea and vomiting are causes of discomfort and dissatisfaction in patients undergoing cesarean section ${ }^{4}$.

Neuraxial anesthetic techniques are the most commonly indicated for cesarean section due to lower rates of maternal morbidity and mortality and less neonatal depression compared with general anesthesia ${ }^{5}$. The combination of lipophilic opioids with hyperbaric bupivacaine during spinal anesthesia for cesarean section provides reduced latency, longer duration of anesthesia, and better quality of anesthesia without increasing the incidence of neonatal depression ${ }^{6}$. Another known effect of opioids is the prevention and treatment of postoperative shivering ${ }^{7}$.

The objective of this study was to analyze the impact of intrathecal sufentanil administration on the incidence of shivering after cesarean section.

\section{METHOD}

A prospective blinded, randomized clinical trial. Patients were invited to participate in the study immediately before anesthesia for cesarean section. The study included pregnant women at term, undergoing low-risk cesarean section under spinal anesthesia, ASA status I or II, who agreed to participate by 
signing the informed consent. Pregnant women in labor, febrile, obese (body mass index $>35 \mathrm{~kg} \cdot \mathrm{m}^{-2}$ ), with pregnancy-induced hypertension, who had third or more cesarean sections, with failure of anesthesia or complication requiring transfusion were excluded from the study.

Patients were monitored by pulse oximetry, cardioscope in DII, and noninvasive blood pressure every three minutes, and venous access was obtained in the upper limb with a $20 \mathrm{G}$ catheter. Patients received $500 \mathrm{~mL}$ intravenous Ringer's lactate at room temperature during the blockade. Axillary temperature of patients was measured by digital thermometer with the arm held close to the body.

With the patient in the sitting position, lumbar puncture was performed at L3-L4 with a 27G Quincke needle. At this time, patients were randomly assigned to two groups (using a sequence of numbers drawn in which odd numbers were allocated in Group I and even numbers in Group II). In Group I, $10 \mathrm{mg}$ of $0.5 \%$ hyperbaric bupivacaine combined with $80 \mathrm{mcg}$ of morphine and $2.5 \mathrm{mcg}$ of sufentanil were administered. In Group II, $10 \mathrm{mg}$ of $0.5 \%$ hyperbaric bupivacaine combined with $80 \mathrm{mcg}$ of morphine were administered. The injection rate was $1 \mathrm{~mL}$ every 5 seconds.

Subsequently, patients were placed in the supine position with lateral deviation of the uterus to the left using a pad under the right hip. According to the institution routine, all patients underwent vesical catheterization, and segmental cesarean section was performed with Pfannenstiel incision. No changes were made to control operating room or post-anesthesia care unit (PACU) routines after anesthesia.

After blockade, hydration with $10 \mathrm{~mL} \cdot \mathrm{kg}^{-1} \cdot \mathrm{h}^{-1}$ of Ringer lactate was maintained. After birth, $1 \mathrm{~g}$ of cefazolin and 10 units of oxytocin in $500 \mathrm{ml}$ of Ringer lactate were administered by infusion. For treatment of symptomatic or non-symptomatic hypotension, bolus dose of 5-10 mg ephedrine was used. If the patients reported pain during the surgery, bolus dose of $500 \mathrm{mcg}$ alfentanil was administered and the patient excluded from the study. After surgery, patients were referred to the PACU, where temperature was measured by the same method and the patient evaluated for signs of shiver by an investigator blinded to the patient's group allocation.

To determine the incidence of shivering in the PACU, the scale proposed by Crossley and Mahajan was used ${ }^{8}$.

$$
\begin{aligned}
0= & \text { no shivering; } \\
1= & \text { One or more of the following: piloerection, peripheral } \\
& \text { vasoconstriction, peripheral cyanosis with no other } \\
& \text { cause, but no musche activity; } \\
2= & \text { visible muscular activity confined to one muscle } \\
& \text { group; } \\
3= & \text { visible muscular activity in more than one muscle } \\
4= & \text { gross muscular activity involving the whole body. }
\end{aligned}
$$

For data file and analysis, the program SPSS v 17.0 (IBM) was used. One study reported that the incidence of shivering after cesarean section is $47 \%{ }^{9}$. To detect a $30 \%$ reduction in the incidence of shivering in the sufentanil group, the minimum number of patients in each group was calculated at 40 , accepting a $5 \%$ alpha error and $20 \%$ beta error.
Data are presented as mean \pm standard deviation or absolute frequency (percentage). To analyze the differences between quantitative variables according to groups the Student's $t$ test was used. Relative risk (95\% confidence interval) was calculated between groups regarding the incidence of shivering (defined as an index on the Crossley scale $\geq 1$ ). The statistical significance level was $95 \%$.

\section{RESULTS}

From March 2010 to June 2011, 94 patients were included in the study. Of these, 14 were excluded (9 from Group I and 5 from Group II) due to lack of adherence to protocol. Demographic characteristics, duration of surgery, and temperature variation were not different among patients who completed the protocol. The final study sample consisted of 80 patients equally distributed between two groups. Patients' demographic and obstetric characteristics are shown in Table I. There were no significant differences between groups.

In both groups, there was a decrease in axillary temperature of patients after cesarean section $(p<0.001)$. This decrease, however, did not differ between groups. Data are presented in Table II.

The group of patients who received intrathecal sufentanil had a lower incidence of shivering in the PACU compared to the group without administration of sufentanil. The incidence was $62.5 \%$ in Group II (25/40) and $32.5 \%$ in Group I (13/40) $(\mathrm{p}<0.007)$, relative risk $0.53(95 \% \mathrm{Cl} 0.32-0.87)$.

Table I - Demographic and Surgical Characteristics of Patients Enrolled in the Study

\begin{tabular}{llll}
\hline & Group I & Group II & p \\
\hline Age (years) & $26.8 \pm 5.8$ & $27.4 \pm 6.6$ & 0.66 \\
Gestational Age (weeks) & $39.3 \pm 1.1$ & $39.3 \pm 1.0$ & 0.98 \\
$\begin{array}{l}\left.\text { Body Mass Index (kg.m }{ }^{-2}\right) \\
\begin{array}{l}\text { Duration of cesarean section } \\
\text { (minutes) }\end{array}\end{array}$ & $29.3 \pm 4.7$ & $29.2 \pm 4.1$ & 0.93 \\
\hline
\end{tabular}

Table II - Axillary Temperature Pre- and Post-Cesarean Section and its Variation in Patients Enrolled in the Study

\begin{tabular}{llll}
\hline & Group I & Group II & p \\
\hline Pre-temperature $\left({ }^{\circ} \mathrm{C}\right)$ & $36.8 \pm 0.4$ & $36.9 \pm 0.3$ & 0.66 \\
Post-temperature $\left({ }^{\circ} \mathrm{C}\right)$ & $35.8 \pm 0.5$ & $35.7 \pm 0.5$ & 0.35 \\
Temperature range $\left({ }^{\circ} \mathrm{C}\right)$ & $1.02 \pm 0.49$ & $1.14 \pm 0.53$ & 0.21 \\
\hline
\end{tabular}

\section{DISCUSSION}

The most important finding of this study was a $30 \%$ reduction in the incidence of shivering after cesarean section with the administration of intrathecal sufentanil $2.5 \mathrm{mcg}$.

The temperature regulating system of mammals is divided into three components: thermosensors and afferent neural pathways, integration system of thermal inputs, and effector pa- 
thways (autonomic and behavioral). The lateral spinothalamic tract is the main afferent pathway, projecting to the hypothalamic regulatory center and nuclei in pons and midbrain. There is a modulation of neural transmission by the nucleus raphe magnus (inhibitor) and locus subcoeruleus (facilitator). The efferent pathway begins in the hypothalamus, makes multiple connections with the reticular formation in the midbrain, pons, and medulla, and ends at the alpha-motor neurons. The main reactions activated by efferent pathways in response to hypothermia are vasoconstriction, nonshivering thermogenesis (described in neonates), and shivering ${ }^{7}$. Shivering is an oscillatory and involuntary muscle contraction that increases metabolic heat production. In addition to heat, there is marked increase in oxygen consumption and carbon dioxide production ${ }^{10}$ with potential risk of complications in patients with cardiovascular or pulmonary impairment.

Neuraxial block causes loss of thermoregulation below the level of blockage. The vasodilation occurring below the level of blockage is presumably responsible for body heat redistribution from central compartment to peripheral compartment ${ }^{11}$. There is a normal shivering reflex in response to the drop in central temperature ${ }^{12}$.

However, body temperature is seldom measured during conduction anesthesia ${ }^{13}$, although there is evidence that both regional anesthesia and general anesthesia are associated with hypothermia. Patients also do not realize they are hypothermic ${ }^{12}$. A review study found that in an analysis of 21 articles, a median incidence of shivering $(55 \%)$ was noted after neuroaxial anesthesia ${ }^{11}$. It was reported that advanced age and high level of spinal block are risk factors for hypothermia after spinal anesthesia ${ }^{14}$. This observation is important in the obstetric care setting, as higher levels of blockade are required during cesarean section to prevent pain during surgery. This variable was not controlled in this study, but it was shown that with 3 or $4 \mathrm{~mL}$ of anesthetic solution there is no difference in maximum block level reached in spinal anesthesia for cesarean section with hyperbaric bupivacaine $(10 \mathrm{mg})$ and of sufentanil $(5 \mathrm{mcg})^{15}$. This difference of $1 \mathrm{~mL}$ is greater than the difference in volume of anesthetic solution in this study $(0.5 \mathrm{~mL})$. Other factors, such operating room temperature, duration of surgery, and body mass index were not described as risk factors for hypothermia during regional anesthesia ${ }^{14}$.

Many drugs have been tested for treatment or prevention of postoperative shivering: meperidine ${ }^{16,17}$, alfentanil ${ }^{18}$, tramadol ${ }^{19}$, pentazocine ${ }^{20}$, clonidine ${ }^{21}$, midazolam ${ }^{22}$, amitriptyline ${ }^{23}$, magnesium sulphate ${ }^{24}$, ondansetron ${ }^{16}$, ketanserin ${ }^{21}$, and ketamine ${ }^{25}$. Most studies reported that meperidine has a more prominent effect on prevention and treatment of postoperative shivering than other opioids, presumably for being a $\mu$ - and k-receptor antagonist, unlike $\mu$-receptor agonists (morphine, fentanyl, sufentanil). Moreover, the non-opioid effects of meperidine may be associated with its anti-shivering action, such as monoamine reuptake inhibition, NMDA receptor antagonism, and stimulation of $\alpha-2$ receptors ${ }^{7}$.

Neuraxial opioid administration is widely used for acute and chronic pain treatment. When opioid is administered in the subarachnoid space, it can act in non-specific sites of white matter or specific receptors in the dorsal horn of the spinal cord. There is also the rostral redistribution to cerebrospinal fluid, a factor responsible for the incidence of late respiratory depression, fortunately rare. A certain amount of the drug diffuses into the epidural space and conveyed to the venous system. The clinical effects observed in patients are the result of these three routes of drug distribution. The hydrophilic character of morphine provides late onset (1-2 hours), longer duration (18-24 hours), and greater spread of analgesia. Lipophilic opioids (fentanyl and sufentanil) provide faster onset of action (5-10 minutes), but with shorter duration of action (4-6 hours) and more restricted body surface area of analgesia ${ }^{26}$.

Injection of opioids into the subarachnoid space has been used specifically for prevention of shivering after cesarean section. Intrathecal meperidine $0.2 \mathrm{mg} \cdot \mathrm{kg}^{-1}$ associated with hyperbaric bupivacaine $0.75 \%$ was effective in reducing the incidence and intensity of shivering after cesarean section ${ }^{27}$. Prevention of shivering rather than treatment after its onset and non-administration of opioids to a patient due to the possibility of inducing nausea and vomiting were reported as two advantages of using meperidine administered by this route. Another study confirmed these results using a fixed dose of $10 \mathrm{mg}$ intrathecal meperidine ${ }^{28}$. These authors found no increased incidence of nausea and vomiting in patients treated with intrathecal meperidine. However, in addition to the postoperative analgesic effect of intrathecal meperidine in obstetric patients, other authors found $40 \%$ increase in the incidence of intraoperative nausea and vomiting 29 .

Intrathecal fentanyl $20 \mathrm{mcg}$ was also evaluated for prevention of shivering after cesarean section and showed a $30 \%$ reduction in its incidence ${ }^{30}$. Our results are in agreement with the data found in these studies, and there are authors who suggest the use of intrathecal meperidine or fentanyl for prevention of postoperative shivering ${ }^{11}$.

Low-dose sufentanil has been reported as safe to both mother and fetus. Hemodynamic and acid-base status preservation and absence of side effects have been demonstrated ${ }^{31}$. Other authors reported a high incidence of pruritus ${ }^{6}$.

Administration of a lipophilic and a hydrophilic opioid has been used in obstetrics. This strategy allows maximum benefit of both drugs. Sufentanil improves the quality of spinal anesthesia during intraoperative and immediate postoperative period and morphine has the ability to reduce pain levels up to 24 hours ${ }^{32}$.

In the institution where the study was conducted, parenteral fluid warming is not routinely used for cesarean section (medium surgery). Recent recommendations indicate the use of fluid warming in cases of emergency obstetric hemorrhage 5 . However, benefits have been reported from fluid warming in the perioperative period in routine obstetric practice. Recently, less variation in maternal temperature after cesarean section was reported; however, with no reduction in the incidence of shivering ${ }^{33,34}$. Conflicting results have been found in these two studies regarding the best fetal acid-base balance and higher Apgar scores as a result of fluid warming. Fluid warming 
is a low-cost measure and should be normally used because of the proven deleterious effects of hypothermia in the general surgical population.

One limitation of this study was the use of axillary temperature to assess heat loss and not core temperature. The axillary temperature, however, may be used to measure core temperature, except in extreme body temperature changes ${ }^{12}$.

The present study suggests that the addition of sufentanil to hyperbaric bupivacaine and morphine during spinal anesthesia for cesarean section provides a decrease in the incidence of shivering in the immediate postoperative period.

\section{ACKNOWLEDGEMENTS}

The author is grateful to colleagues and staff of the PACU for their cooperation in data collection. 
5. Practice guidelines for obstetric anesthesia: an updated report by the American Society of Anesthesiologists Task Force on Obstetric Anesthesia - Anesthesiology, 2007;106:843-863.

6. Braga Ade F, Braga FS, Poterio GM, Pereira RI, Reis E, Cremonesi E - Sufentanil added to hyperbaric bupivacaine for subarachnoid block in Caesarean section. Eur J Anaesthesiol, 2003;20:631-635.

7. De Witte J, Sessler DI - Perioperative shivering: physiology and pharmacology. Anesthesiology, 2002;96:467-484.

8. Crossley AW, Mahajan RP - The intensity of postoperative shivering is unrelated to axillary temperature. Anaesthesia, 1994;49:205-207.

9. Butwick AJ, Lipman SS, Carvalho B - Intraoperative forced air-warming during cesarean delivery under spinal anesthesia does not prevent maternal hypothermia. Anesth Analg, 2007;105:1413-1419.

10. Ciofolo MJ, Clergue F, Devilliers C, Ben Ammar M, Viars P - Changes in ventilation, oxygen uptake, and carbon dioxide output during recovery from isoflurane anesthesia. Anesthesiology 1989;70:737-741.

11. Crowley LJ, Buggy DJ - Shivering and neuraxial anesthesia. Reg Anesth Pain Med, 2008;33:241-252.

12. Sessler $\mathrm{DI}-$ Temperature monitoring and perioperative thermoregulation. Anesthesiology, 2008;109:318-338.

13. Arkilic CF, Akca O, Taguchi A, Sessler DI, Kurz A - Temperature monitoring and management during neuraxial anesthesia: an observational study. Anesth Analg, 2000;91:662-666.

14. Frank SM, El-Rahmany HK, Cattaneo CG, Barnes RA - Predictors of hypothermia during spinal anesthesia. Anesthesiology, 2000;92:13301334.

15. Braga Ade F, Frias JA, Braga FS, Pinto DR - Spinal block with $10 \mathrm{mg}$ of hyperbaric bupivacaine associated with 5 microg of sufentanil for cesarean section. Study of different volumes. Rev Bras Anestesiol, 2010;60:121-9, 69-73.

16. Kelsaka E, Baris S, Karakaya D, Sarihasan B - Comparison of ondansetron and meperidine for prevention of shivering in patients undergoing spinal anesthesia. Reg Anesth Pain Med, 2006;31:40-45.

17. Kranke P, Eberhart LH, Roewer N, Tramer MR - Pharmacological treatment of postoperative shivering: a quantitative systematic review of randomized controlled trials. Anesth Analg, 2002;94:453-460.

18. Wrench IJ, Cavill G, Ward JE, Crossley AW - Comparison between alfentanil, pethidine and placebo in the treatment of post-anaesthetic shivering. Br J Anaesth, 1997;79:541-542.

19. Mohta M, Kumari N, Tyagi A, Sethi AK, Agarwal D, Singh M - Tramadol for prevention of postanaesthetic shivering: a randomised doubleblind comparison with pethidine. Anaesthesia, 2009;64:141-146.

20. Terasako K, Yamamoto $M$ - Comparison between pentazocine, pethidine and placebo in the treatment of post-anesthetic shivering. Acta Anaesthesiol Scand, 2000;44:311-312.

21. Joris J, Banache M, Bonnet F, Sessler DI, Lamy M - Clonidine and ketanserin both are effective treatment for postanesthetic shivering. Anesthesiology, 1993;79:532-539.

22. Honarmand A, Safavi MR - Comparison of prophylactic use of midazolam, ketamine, and ketamine plus midazolam for prevention of shivering during regional anaesthesia: a randomized double-blind placebo controlled trial. Br J Anaesth, 2008;101:557-562.

23. Tsai YC, Chu KS - A comparison of tramadol, amitriptyline, and meperidine for postepidural anesthetic shivering in parturients. Anesth Analg, 2001;93:1288-1292.

\section{REFERENCES}

1. Biazzotto CB, Brudniewski M, Schmidt AP, Auler Junior JO - [Perioperative hypothermia]. Rev Bras Anestesiol, 2006;56:89-106.

2. Kurz A - Thermal care in the perioperative period. Best Pract Res Clin Anaesthesiol, 2008;22:39-62.

3. Albergaria VF, Lorentz MN, Lima FA - [Intra and postoperative tremors: prevention and pharmacological treatment]. Rev Bras Anestesiol, 2007;57:431-444.

4. Capogna G, Celleno D - Improving epidural anesthesia during cesarean section: causes of maternal discomfort or pain during surgery. Int J Obstet Anesth, 1994;3:149-152.

24. Wadhwa A, Sengupta $P$, Durrani $J$ et al. - Magnesium sulphate only slightly reduces the shivering threshold in humans. $\mathrm{Br} \mathrm{J}$ Anaesth, 2005;94:756-762.

25. Sagir O, Gulhas N, Toprak H, Yucel A, Begec Z, Ersoy O - Control of shivering during regional anaesthesia: prophylactic ketamine and granisetron. Acta Anaesthesiol Scand, 2007;51:44-49.

26. Rathmell JP, Lair TR, Nauman B - The role of intrathecal drugs in the treatment of acute pain. Anesth Analg, 2005;101:S30-43.

27. Roy JD, Girard M, Drolet $P$ - Intrathecal meperidine decreases shivering during cesarean delivery under spinal anesthesia. Anesth Analg, 2004;98:230-234.

28. Hong JY, Lee IH - Comparison of the effects of intrathecal morphine and pethidine on shivering after Caesarean delivery under combinedspinal epidural anaesthesia. Anaesthesia, 2005;60:1168-72. 
29. Yu SC, Ngan Kee WD, Kwan AS - Addition of meperidine to bupivacaine for spinal anaesthesia for Caesarean section. $\mathrm{Br} \mathrm{J}$ Anaesth, 2002;88:379-383.

30. Techanivate A, Rodanant O, Tachawattanawisal W, Somsiri T - Intrathecal fentanyl for prevention of shivering in cesarean section. $J$ Med Assoc Thai, 2005;88:1214-1221.

31. Castro LFL, Serafim MM, Côrtes CAF, Neto NLdS, Vasconcellos FO, Oliveira AS - Avaliação do estado ácido-básico materno com o uso de sufentanil por via subaracnoidea em diferentes doses para cesarianas e suas repercussões sobre os recém-nascidos. Rev Bras Anestesiol, 2003;53:17-24.

32. Yazigi A, Chalhoub V, Madi-Jebara S, Haddad F, Hayek G - Prophylactic ondansetron is effective in the treatment of nausea and vomiting but not on pruritus after cesarean delivery with intrathecal sufentanilmorphine. J Clin Anesth, 2002;14:183-186.

33. Woolnough M, Allam J, Hemingway C, Cox M, Yentis SM - Intraoperative fluid warming in elective caesarean section: a blinded randomised controlled trial. Int J Obstet Anesth, 2009;18:346-351.

34. Yokoyama K, Suzuki M, Shimada Y, Matsushima T, Bito H, Sakamoto A - Effect of administration of pre-warmed intravenous fluids on the frequency of hypothermia following spinal anesthesia for Cesarean delivery. J Clin Anesth, 2009;21:242-248. 